\title{
The Use of Chicken Legs for Teaching Wound Closure Skills
}

\author{
P. N. Khalil1 ${ }^{1}$ M. Siebeck ${ }^{1}$, W. Mutschler' ${ }^{2}$, K.-G. Kanz ${ }^{3}$ \\ ${ }^{1}$ Division of General and Visceral Surgery, ${ }^{2}$ Division of Trauma Surgery, ${ }^{3}$ Division of Surgical Emergency Medicine, \\ Department of Surgery, Downtown Medical Centre, Ludwig-Maximilians University, Munich, Germany
}

\begin{abstract}
Objective: Training models are required to impart surgical skills, like wound closure techniques, prior to practice in patients. In an ideal case, the tissue characteristics of the model are close to those of humans, easy to create and of low cost.

Methods: Here, we describe a model to train students in wound closure technique using conventional chicken legs obtained from the supermarket.

Results: The described model has good tissue characteristics, does not require any lavish preparation and is of minimal cost (0.62 Euro or 0.78 USD).

Conclusions: Chicken legs appear to be an appropriate tool for teaching wound closure techniques.

Key words: Medical undergraduate education, surgery, surgical skills, wound Closure, models, chicken legs
\end{abstract}

\section{INTRODUCTION}

Traumatic wounds or skin lacerations are among the most common injuries, occurring in people of all ages. Given this, it is rational to impart wound evaluation and closure techniques to medical undergraduate students during their surgical curriculum. Although most wounds and tissue defects heal without complication after direct suturing, some wounds require advanced techniques like Z-plasty, V-Y-plasty or an oval-shaped advancement flap to avoid hypertrophic scar formation or disturbance of primary wound healing [1-6]. These advanced techniques may be used to reduce tension on the wound edges and to allow better approximation of the epidermis [1]. Models are warranted to train these surgical skills since they require accurate planning and abstract visualization of shifting and rotating the cutaneous flap. Poor surgical execution can lead to poor skin perfusion and a larger resulting cutaneous defect. Although various teaching models exist for teaching these particular skills, they differ with respect to their required expense and preparation time [7-16]. However, the most important requirement of the particular model should be the ability to transfer validly and reliably [17]. Here, we introduce a new, simple and inexpensive model with this potential: to train wound closure techniques using chicken legs.

\section{Material and Methods}

\subsection{MODEL}

The model uses packed Class A chicken legs (GEKA Frisch+Frost Handels GmbH \& Co. KG, Visbek, Germany) obtained from the supermarket (Aldi-Süd, Mül- heim, Germany) (4 legs $=1100 \mathrm{~g}$ for $2.49 €$ ) that were stored at $4{ }^{\circ} \mathrm{C}$.

\subsection{EQUIPMENT}

The required equipment for training of wound closure technique are an unsterile pad (i) red and blue ink (ii) surgical instruments (forceps, scissor, needle-driver, No. 15 scalpel) and (iii) monofilament 4-0 suture material.

\subsection{Wound Closure}

The chicken legs were first placed on the pad in a semifrozen state at about $4^{\circ} \mathrm{C}$ after removal from the refrigerator. Thereafter, the simulated skin defect was drawn with red ink and the incisional lines for the particular wound closure technique with blue ink. Three different techniques were taught using one leg. The particular incisions were placed and the skin was mobilized as necessary after excision of the defect. The wound closure was completed by single sutures after rotation and swivel of the cutaneous defect.

\section{RESULTS}

The chicken leg demonstrated good tissue properties to train wound closure techniques although we acknowledge its thin cutaneous layer. There was no further preparation of the legs necessary beyond taking the chicken legs from the freezer immediately before usage. The mean weight of one leg was $275 \mathrm{~g}$, which cost $0.62 €$ (0.78 USD). The possible usable skin size was about 134 $\mathrm{cm}^{2}$ allowing a maximum of about 4 wound closure attempts. A demonstration of the single steps of a wound closure with a simulated defect is given in Figure 1. Performance of a Z-plasty is shown as an example.

\section{Discussion}

There are different models available to train wound closure techniques, including bench models, living animals and their limbs and organs [7-16]. The ideal model should come close to the tissue properties of humans and enable the student to transfer skills from the training environment to the patient. Most of the available training models run in workshops rather than being incorporated into a structured curriculum, which is most likely attributed to the efforts needed for preparation and expenses. Therefore, the training model should be easy to obtain and to prepare and have low costs. Finally, the training model should not be open to ethical concerns and should be harmless in terms of the trans- 

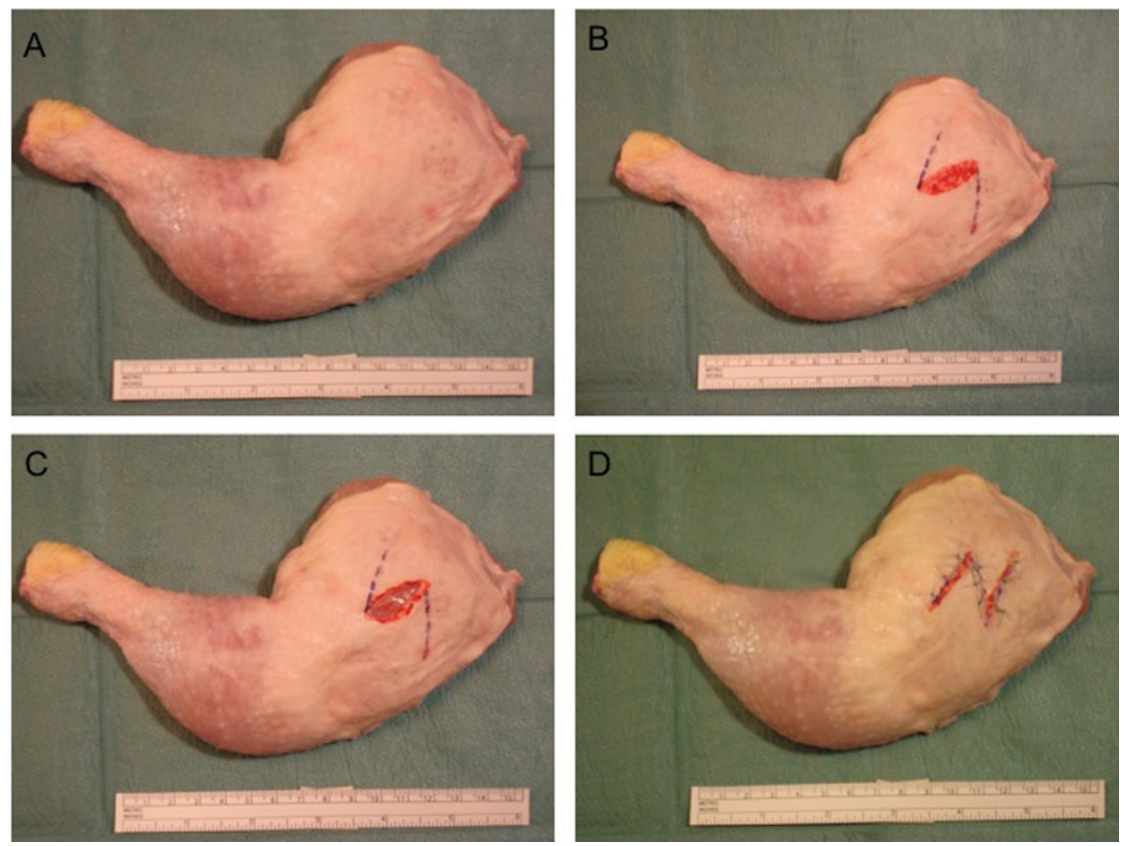

Fig. 1. A chicken leg as obtained from the supermarket $(\mathrm{A})$, after drawing the simulated defect of about $3 \mathrm{~cm}$ in length (red) and incisional lines for the z-plasty (blue) at an angle of about $60^{\circ}$ (B), excised simulated cutaneous defect (C), completed Z-plasty (A).

mission of infectious disease. Almost all bench models require some time for preparation, and the tissue condition of the form material is not similar to those of humans. The porcine digit represents one of the most frequently used models to impart wound closure techniques. However, its skin is very tough and, due to the small circumference and size of the digit, has little usable surface. Other models, using detached rat skin that was previously used for research purposes, require tremendous efforts for set-up. Using living animals for teaching wound closure which allows to see the perfusion result of the lifted flap, as advocated by one group, seems to be questionable based on ethical concerns and because of the high costs and necessary preparation time [13]. Taking this into account, chicken legs closely meet the requirements of a trainings model for teaching wound closure techniques in our hands. The model itself does not need any time for preparation and is inexpensive, at about $0.62 €(0.78$ USD) for a chicken leg. The curved plane of the chicken legs allows simulation of a more challenging wound closure, where exact mobilization of the surrounding tissue is needed (as compared to the simple plane surface present in conventional bench models). The tissue condition and size are suitable for training and allowing multiple attempts. However, gentle tissue handling is required due to the thin skin of the chicken legs what need not to be a disadvantage as it also needed in surgical practice when closing wound at the patients hand or face.

\section{REFERENCES}

1. Reichman EF, Kolm L. Advanced wound closure techniques. In Reichman EF and Simon RR (eds.): Emergency Medicine Procedures, McGraw-Hill Medical Publishing Division, New York, 2004, pp 736-747.

2. Hove CR, Willams EF 3rd, Rodgers BJ. Z-plasty: a concise review. Facial Plast Surg 2001; 17: 289-294.

3. Jackson EA. The V-Y plasty in the treatment of fingertip ampitations. Am Fam Physician 2001; 64: 455-458

4. Wu T. Plastic surgery made easy - simple techniques for closing skin defects and improving cosmetic results. Aust Fam Physicain 2006; 35: 492-496.
5. Goldman GD. Rotation flaps. Dermatol Surg 2005; 31: 10061013.

6. Chen EH, Johnson TM, Ratner D. Introduction to flap movement: reconstruction of five similar nasal defects using different flaps. Dermatol Surg 2005; 31: 982-985

7. Tokuhara KG, Boldt DW, Yamamoto LG. Teaching suturing in a workshop setting: a comparison of several models. Hawaii Med J 2004; 63: 258-259.

8. Cole FL, Ramirez EG. Beef tongue: a model for teaching complex wound closure to emergency nurse practitioner students. J Emerg Nurs 2002; 28: 467-468.

9. Snell GF. A method for teaching techniques of office surgery. J Fam Pract 1978; 7: 987-990.

10. Dinsmore RC, North JH. Basic skin flaps for the general surgeon: a teaching method. South Med J 2000; 93: 783-786.

11. Lawrence TL, Wiviott W. Use of turkey skins for surgical teaching. J Fam Pract 1978; 6: 69-70.

12. Wanzel KR, Matsumoto ED, Hamstra SJ, Anastakis DJ. Teaching technical skills: training on a simple, inexpensive, and portable model. Past Reconstr Surg 2002; 109: 258-263.

13. Anders KH, Goldstein BG, Lesher JL Jr, Shimp RG, Chalker DK. The use of live pigs in the surgical training of dermatology residents. J Dermatol Surg Oncol 1989; 15: 734-736.

14. Kuwahara RT, Rasberry R. Pig head model for practice cutaneous surgery. Dermatol Surg 2000; 26: 401-402.

15. Altinyazar HC, Hosnuter M, Unalacak M, Koca R, Babuccu O. A training model for cutaneous surgery. Dermatol Surg 2003; 29: 1122-1124.

16. Sillitoe AT, Plat A. The Z-plasty simulator. Ann R Coll Surg 2004; 86: 304-305.

17. Cosman P, Hemli JM, Ellis AM, Hugh TJ. Learning the surgical craft: a review of skills training options. ANZ J Surg 2007; 77: 838-845.

Received: March 10, 2009 / Accepted:

Address for correspondence:

Priv.-Doz. Dr. med. Philipe N. Khalil

Division of General and Visceral Surgery

Department of Surgery

Downtown Medical Centre

Ludwig-Maximilians University

Nußbaumstr. 20

80336 München

Germany

E-mail: philipe.khalil@med.uni-muenchen.de 